\title{
Recovery of photosynthetic activity of resurrection plant Haberlea rhodopensis from drought- and freezing-induced desiccation
}

\author{
K. GEORGIEVA*,, G. MIHAILOVA*, M. VELITCHKOVA**, and A. POPOVA** \\ Institute of Plant Physiology and Genetics, Bulgarian Academy of Sciences, Acad. G. Bonchev str., Bl. 21, \\ 1113 Sofia, Bulgaria* \\ Institute of Biophysics and Biomedical Engineering, Bulgarian Academy of Sciences, Acad. G. Bonchev str., \\ Bl. 21, 1113 Sofia, Bulgaria**
}

\begin{abstract}
The recovery of photosynthetic activity during rehydration of Haberlea rhodopensis from drought- and freezing-induced desiccation were investigated. The water uptake during the initial $15 \mathrm{~h}$ was slow thus preventing cellular damages. The results showed faster recovery of quantum efficiency of PSII in plants rehydrated after freezing stress (RAF) compared to plants rehydrated after drought stress (RAD) and the most significant differences between them were evident after 9-15 $\mathrm{h}$ of rehydration. Following rehydration, PSI activity recovered faster compared to PSII and in contrast to PSII, its activity was higher in RAD compared to RAF plants. During the first hours of rehydration, prominent alterations in energy transfer between photosynthetic complexes occurred as revealed by $77 \mathrm{~K}$ fluorescence of isolated thylakoids. High proportion of thermal energy dissipation in dry plants and during the first hours of rehydration protects them from photooxidation; the role of PSII reaction center quenching during the recovery was suggested.
\end{abstract}

Additional key words: $77 \mathrm{~K}$ fluorescence spectra; chlorophyll fluorescence; desiccation tolerance.

\section{Introduction}

In natural habitats, plants are constantly exposed to various kinds of environmental stresses that adversely affect their growth and productivity. In addition, the ongoing climate changes are known to have an enormous impact on current plant diversity. That is why it is very important to unravel the mechanisms that plants have evolved to cope with stress conditions. Understanding plant responses to environmental constraints is important for identifying strategies to improve tolerance to abiotic stresses in crop species and for predicting the ecological distribution of natural vegetation under the projected climate changes.

Resurrection plants are unique among vascular angiosperms with their ability to survive desiccation to air-dry state. Desiccation tolerance of vegetative tissue is uncommon phenomenon and consists in losing more than $95 \%$ of the protoplasmic water or 'the ability to survive drying to, or below, the absolute water content of $0.1 \mathrm{~g}\left(\mathrm{H}_{2} \mathrm{O}\right) \mathrm{g}^{-1}$ (dry mass), this being equivalent to air-dryness at $50 \%$ relative humidity and $20^{\circ} \mathrm{C}$ and corresponding to a water potential of $\leq-100 \mathrm{MPa}$ (Vertucci and Farrant 1995). Only 300 species of resurrection plants are reported and most of them are living in the southern hemisphere - Africa, America, and Australia (Gaff and Oliver 2013). One family of resurrection plants is distributed in the northern hemisphere (Europe and Asia) - Gesneriaceae. Five species from three genera are located in Europe (Haberlea rhodopensis, Ramonda serbica, Ramonda nathaliae, Ramonda myconi, and Jankaea heldreichii (Rakić et al. 2014, Georgieva et al. 2017a, Gashi et al. 2019, Fernández-Marín et al. 2020). Boea hygrometrica, Paraboea rufescens, and few other species could be found in Asia (Huang et al. 2012, Liu et al. 2019). Haberlea rhodopensis is a perennial herbaceous rock poikilohydric plant, forming dense tufts of leaves, every rosette bearing in spring one to five flower-stalks. This Tertiary relict emerged in the late Oligocene (Petrova et al. 2015) and is characterized with a high ecological plasticity, growing at altitude from $136 \mathrm{~m}$ to near $1600 \mathrm{~m}$ at different temperature, water, and light conditions (Daskalova et al. 2011). Resurrection plants are excellent model systems for studying the mechanisms

Received 20 March 2020, accepted 27 May 2020.

${ }^{+}$Corresponding author; e-mail: georgieva.katya.m@,gmail.com, katya@bio21.bas.bg

Abbreviations: $\left(1-\mathrm{F}_{\mathrm{v}}{ }^{\prime} / \mathrm{F}_{\mathrm{m}}{ }^{\prime}\right)-$ the relative proportion of the energy absorbed and dissipated as heat in the PSII antennae; $\left(1-\mathrm{q}_{\mathrm{P}}\right)-$ excitation pressure; $\mathrm{Chl}$ - chlorophyll; $\mathrm{E}_{470} / \mathrm{E}_{436}$ - the ratio of intensities of bands at 470 and $436 \mathrm{~nm}$ in the excitation spectra of fluorescence emitted at $685 \mathrm{~nm} ; \mathrm{E}_{680} / \mathrm{E}_{650}$ - the ratio of intensities of bands at 680 and $650 \mathrm{~nm}$ in excitation spectra of fluorescence emitted at $735 \mathrm{~nm} ; \mathrm{F}_{685} / \mathrm{F}_{695}$ - the ratio of intensities of fluorescence bands at 685 and $695 \mathrm{~nm} ; \mathrm{F}_{735} / \mathrm{F}_{685}-$ the ratio of intensities of fluorescence bands at 735 and $685 \mathrm{~nm} ; \mathrm{F}_{\mathrm{v}} / \mathrm{F}_{\mathrm{m}}$ - maximal quantum yield of PSII photochemistry; RAD - rehydrated after drought stress; RAF - rehydrated after freezing stress; RWC - relative water content; $\Phi_{\text {PSII }}-$ effective quantum yield of PSII photochemistry.

Acknowledgements: This work was supported by the Bulgarian National Science Fund, Ministry of Education and Science (Project КП-06-H21/8). 
underlying desiccation tolerance. Desiccation-tolerant plants must be able to limit the damage to a repairable level, maintain physiological integrity in the dried state, and mobilize mechanisms upon rehydration that repair damages during desiccation and subsequent rehydration (Bewley 1979, Oliver et al. 2000). Resurrection plants tolerate desiccation through a set of different mechanisms, including the downregulation of metabolism, upregulation of housekeeping and novel antioxidants to minimize free radical damage, subcellular reorganization to minimize mechanical damage associated with turgor loss, accumulation of specific proteins, and maintenance of the structure and function of macromolecules through the accumulation of disaccharides and other compatible compounds (for review see Farrant et al. 2007, Morse et al. 2011, Giarola et al. 2017, Liu et al. 2019). Desiccation tolerance can be achieved either by mechanisms that are based on the protection of cellular integrity or mechanisms that are based on the repair of desiccation or rehydration induced cellular damage (Bewley and Oliver 1992). Most of the studies on these plants have focused on the characterization of protection mechanisms in the dehydration phase and thus the rehydration processes of resurrection plants have been scarcely investigated (Giarola and Bartels 2015). In fact, most of the researches are focused on later stages of rehydration when plants regain most of their water content. However, a rapid water uptake upon rehydration is a serious stress factor for plants which could induce cellular damages (Oliver et al. 2000). Several activities are necessary during rehydration to reestablish the original cellular organization and metabolic activities. These mechanisms are part of the survival strategy of resurrection plants and must be coordinated to permit successful recovery from desiccation.

Photosynthesis is one of the most sensitive processes to environmental stress conditions. The loss of photosynthetic capacity could be triggered by several factors, such as the closure of stomata, degradation of pigments, loss of photosynthetic function or destruction of photosynthetic structure (Deng et al. 2003, Peeva and Cornic 2009). $H$. rhodopensis belongs to the group of homoiochlorophyllous resurrection plants which retain most of the chlorophyll (Chl) and maintain their photosynthetic apparatus during desiccation, allowing them to resume photosynthetic activity quickly upon water availability (Georgieva et al. 2007, 2009). However, the high concentration of Chl during desiccation is a source for the production of harmful reactive oxygen species that can induce oxidative stress (Lawlor and Cornic 2002). Thus, preserving the integrity of photosynthetic apparatus is of primary importance for recovery of plants after stress treatment (Georgieva and Mihailova 2016).

In contrast to the most resurrection plants, $H$. rhodopensis is exposed to and can withstand freezing temperatures during winter. The first data available in the literature about tolerance of resurrection plants ( $R$. myconi) to low temperatures are from Kappen (1966). Recently, Fernández-Marín et al. $(2018,2020)$ showed that $R$. myconi can tolerate freezing temperatures during winter. The effect of short-term low temperature treatment $(3 \mathrm{~d}$ at $4^{\circ} \mathrm{C}$ ) on the metabolite changes in $H$. rhodopensis was investigated (Benina et al. 2013). Our previous studies showed that when the night temperatures drop down to -2 to $-4^{\circ} \mathrm{C}$, leaf rolling starts but with the rise of temperature during the day leaves unfold (Georgieva et al. 2018). However, exposure of plants to about $-10^{\circ} \mathrm{C}$ resulted in a reduction in relative water content of leaves and thereafter they desiccated very quickly to air-dry state (Georgieva et al. 2018). Thus, similar to drought, freezing stress also causes dehydration of plants and they survive the harsh winter conditions in the dry state (Daskalova et al. 2010).

Understanding the response of resurrection angiosperms to dehydration and rehydration is critical for deciphering the mechanisms of how plants cope with the rigors of water loss from their vegetative tissues. For this reason, the investigations of rehydration phenomenon in $H$. rhodopensis, especially after the onset of rewatering of dried plants, are necessary. In addition, the comparison of mechanisms of recovery from drought- and freezinginduced desiccation will contribute for better understanding the strategies for survival of this resurrection plant.

The aim of present study was to investigate and compare the recovery of photosynthetic activity during rehydration of Haberlea rhodopensis plants from droughtand freezing-induced desiccation. The functional activity of photosynthetic apparatus was estimated by measuring the photochemical efficiency of PSII and PSI, the energy interaction between them, and the content of photosynthetic pigments.

\section{Materials and methods}

Desiccation and rehydration of plants: Haberlea rhodopensis Friv. tufts of shade ecotype were initially collected from the Rhodope Mountains and further cultivated in pots with peat soil (Stender, Schermbeck, Germany) under ex situ (outdoor) environmental conditions at least for one year. Part of the plants were transferred to a climatic chamber FytoScope FS 130 (Photon Systems Instruments, Drásov, Czech Republic) and kept at $20 / 18^{\circ} \mathrm{C}$ day/night temperature, $60 \%$ humidity, $12-\mathrm{h}$ photoperiod, and irradiance of $25 \mu \mathrm{mol}$ (photon) $\mathrm{m}^{-2} \mathrm{~s}^{-1}$ for two weeks. Then plants were subjected to drought stress by withholding irrigation and desiccated to air-dry state. Desiccation was performed during summer (July-August 2019) and plants were rehydrated in August-September to follow natural processes. Before rehydration, the plants were kept in airdry state for two weeks. The other plants were left outdoor and were exposed to cold and freezing temperatures in natural conditions during autumn and winter (November 2018-February 2019). The light intensity during the experiment was $30-60 \mu \mathrm{mol}\left(\right.$ photon) $\mathrm{m}^{-2} \mathrm{~s}^{-1}$. Low positive temperatures did not influence the relative water content (RWC) of leaves. But when the temperature dropped to about $-10^{\circ} \mathrm{C}$, plant's dehydration started and they were in air-dry state during the winter (about three months). Dry plants were taken from outside and their rehydration was performed in March similarly to the natural conditions.

Rehydration of plants desiccated to air-dry state as a result of drought or freezing stress was carried out in 
laboratory conditions at $21-23^{\circ} \mathrm{C}$ and light intensity of 25-30 $\mu$ mol(photon) $\mathrm{m}^{-2} \mathrm{~s}^{-1}$. At first the soil was well irrigated and then the pots were transferred in a modified desiccator where the desiccant at the bottom was replaced by water, providing permanent high humidity by a water pump. The measurements were conducted on dry leaves $(0 \mathrm{~h})$ and after $3,5,7,9,15,24 \mathrm{~h}$, and $7 \mathrm{~d}$ of rehydration.

Relative water content (RWC): The RWC of H. rhodopensis leaves was determined gravimetrically by weighing them before and after oven-drying at $80^{\circ} \mathrm{C}$ to a constant mass and expressed as percentage of water content in dehydrated tissue compared to water-saturated tissues, using the equation: RWC $[\%]=(F M-D M) /(T M-D M)$ $\times 100$, where FM - fresh mass, DM - dry mass, and TM turgid mass. TM was measured on leaves maintained for $12-16 \mathrm{~h}$ at $4^{\circ} \mathrm{C}$ in the dark floating on water.

Pigments: Chl $a$, Chl $b$, and total carotenoids were extracted from leaf disks with $80 \%$ acetone. The pigment content was determined spectrophotometrically by Multiskan Spectrum (Thermo Fisher Scientific, Waltham, Massachusetts, USA) using the equations of Lichtenthaler (1987). The data were calculated on a dry mass basis.

Chl $\boldsymbol{a}$ fluorescence induction: Chl $a$ fluorescence induction was measured with a portable fluorometer PAM-2500 (Heinz Walz GmbH, Effeltrich, Germany). The leaves were dark-adapted for $15 \mathrm{~min}$ and PAR of $90 \mu \mathrm{mol}$ (photon) $\mathrm{m}^{-2} \mathrm{~s}^{-1}$ was used for the measurements. The temperature during measurements was $21-23^{\circ} \mathrm{C}$. All used basic parameters were given by PamWin-3 software (Heinz Walz $G m b H$, Effeltrich, Germany). The maximum efficiency of PSII photochemistry was calculated as $\mathrm{F}_{\mathrm{v}} / \mathrm{F}_{\mathrm{m}}$ immediately after the predarkening period. The actual efficiency of PSII electron transport during illumination was estimated at steady state as $\Phi_{\mathrm{PSII}}=\left(\mathrm{F}_{\mathrm{m}}{ }^{\prime}-\mathrm{F}_{\mathrm{s}}\right) / \mathrm{F}_{\mathrm{m}}{ }^{\prime}($ Genty et al. 1989$)$, where $F_{m}{ }^{\prime}$ is the maximum fluorescence and $F_{s}$ is the steady-state fluorescence in light-adapted state. Excitation pressure of PSII, which gives an approximate measure of the reduction state of the first electron acceptor $\mathrm{Q}_{\mathrm{A}}$ of PSII, was calculated as $1-\mathrm{q}_{\mathrm{P}}$, as $\mathrm{q}_{\mathrm{P}}$ is determined by the equation $\mathrm{q}_{\mathrm{p}}=\left(\mathrm{F}_{\mathrm{m}}{ }^{\prime}-\mathrm{F}_{\mathrm{s}}\right) /\left(\mathrm{F}_{\mathrm{m}}{ }^{\prime}-\mathrm{F}_{0}\right)($ van Kooten and Snel 1990). The relative proportion of the energy absorbed and dissipated as heat in the PSII antennae (referred as thermal energy dissipation in the antenna) was estimated by $1-\left(\mathrm{F}_{\mathrm{v}}{ }^{\prime} / \mathrm{F}_{\mathrm{m}}{ }^{\prime}\right)$ (Demmig-Adams et al. 1996). A fraction of light absorbed in PSII antennae that was neither utilized in photosynthetic electron transport nor dissipated thermally, labelled as 'excess' energy was estimated using the equation: Excess $=\mathrm{F}_{\mathrm{v}}{ }^{\prime} / \mathrm{F}_{\mathrm{m}}{ }^{\prime} \times\left(1-\mathrm{q}_{\mathrm{P}}\right)($ Demmig-Adams et al. 1996).

$\mathbf{P}_{700}$ measurements: The redox state of $\mathrm{P}_{700}$ was monitored in vivo as $\triangle \mathrm{A}_{820} \mathrm{~nm}$ absorption changes. A Walz ED $700 D W-E$ emitter/detector unit was connected to a $P A M$ $101 E$ main control unit (Heinz Walz GmbH, Effeltrich, Germany). $\mathrm{P}_{700}$ was oxidized by far-red (FR) light from a photodiode (FR-102, Heinz Walz GmbH, Effeltrich, Germany). Intensity of FR light was $13.4 \mathrm{~W} \mathrm{~m}^{-2}$. FR light was controlled by the PAM 102 unit and applied via the multibranched fiber optic system. The measurement was carried out in the reflection mode. The temperature during measurements was $21-23^{\circ} \mathrm{C}$.

Thylakoid preparation: Thylakoid membranes were prepared as described by Georgieva et al. (2009). Leaves were ground in liquid nitrogen to fine powder, resuspended in buffer A [50 mM HEPES ( $\mathrm{pH} 7.5), 400 \mathrm{mM} \mathrm{NaCl}$, $10 \mathrm{mM} \mathrm{MgCl}, 2 \mathrm{~g} \mathrm{~L}^{-1}$ bovine serum albumin (BSA), $10 \mathrm{mM}$ dithionite, $4 \mathrm{~g} \mathrm{~L}^{-1}$ ascorbate] and centrifuged at $8,600 \times g$ for $5 \mathrm{~min}$ and $4^{\circ} \mathrm{C}$. The pellet was resuspended in buffer A again and centrifuged at $8,600 \times g$ for $10 \mathrm{~min}$, $4^{\circ} \mathrm{C}$. The sample was filtered through two layers of Miracloth (Merck Millipore, Darmstadt, Germany) and cotton wool. The filtrate was centrifuged at $8,600 \times g$ for $10 \mathrm{~min}, 4^{\circ} \mathrm{C}$ and the resulted pellet resuspended in $50 \mathrm{~mL}$ buffer B [50 mM MES (pH 6.0), $150 \mathrm{mM} \mathrm{NaCl}$, $5 \mathrm{mM} \mathrm{MgCl}_{2}, 1 \mathrm{~g} \mathrm{~L}^{-1} \mathrm{BSA}, 0.5 \mathrm{~g} \mathrm{~L}^{-1}$ ascorbate]. Following centrifugation step at $8,600 \times \mathrm{g}$ for $10 \mathrm{~min}, 4^{\circ} \mathrm{C}$, the pellet was resuspended in $150 \mu \mathrm{L}$ buffer $\mathrm{C}$ ( $50 \mathrm{mM}$ MES, pH 6.0, $5 \mathrm{mM} \mathrm{MgCl}_{2}, 15 \mathrm{mM} \mathrm{NaCl}$ ). The $\mathrm{Chl}$ content of thylakoid fractions was determined spectrophotometrically in $80 \%$ acetone by Multiskan Spectrum (Thermo Fisher Scientific, Waltham, Massachusetts, USA) using the equations of Lichtenthaler (1987).

Steady-state low temperature $(77$ K) fluorescence spectra: Low temperature $(77 \mathrm{~K})$ fluorescence emission and excitation spectra of thylakoid membranes were registered by a Jobin Yvon JY3 spectrofluorometer (Division d'Instruments S.A., Longjumeau, France), equipped with a low temperature device and a red sensitive photomultiplier as described in Velitchkova and Popova (2005). Samples from isolated thylakoid membranes at concentration of $10 \mu \mathrm{g} \mathrm{Chl}(a+b) \mathrm{ml}^{-1}$ were transferred into a quartz tube for fluorescence measurement and immediately frozen in liquid nitrogen. Emission spectra were recorded in the region of 660-780 nm under excitation with $436 \mathrm{~nm}$. Excitation spectra for emission at $735 \mathrm{~nm}$ (PSI) were recorded in the red $(700-610 \mathrm{~nm})$ region and excitation spectra of emission from PSII (at $685 \mathrm{~nm}$ ) in the blue region $(500-410 \mathrm{~nm})$. The width of the emission and excitation slits was $4 \mathrm{~nm}$. The spectra were analyzed by Origin 6.0 (OriginLab Co., Northampton, MA, USA).

Statistical analysis: Two rehydration cycles were performed for each group of plants and the measurements of RWC, Chl $a$ fluorescence, and $\Delta \mathrm{A}_{820} \mathrm{~nm}$ absorption changes were repeated three times per cycle using leaves from different plants $(n=6)$. Thylakoids were isolated from $10 \mathrm{~g}$ of leaves sampled from different plants per each time point during rehydration. Comparison of means was made by the Fisher's least significant difference (LSD) test at $P \leq 0.05$ following analysis of variance (ANOVA). A statistical software package (StatGraphics Plus, version 5.1 for Windows, USA) was used. The Pearson's correlation coefficient $(r)$ was used to measure the strength of a linear association between two variables. It was calculated in Microsoft Excel. The formulas return a value between -1 and 1 , where 1 indicates a strong positive 
relationship and -1 indicates a strong negative relationship. A result of zero indicates no relationship at all.

\section{Results}

Recovery of relative water content: Measurements of RWC during recovery of $H$. rhodopensis from droughtand freezing-induced desiccation showed that water uptake during the initial $15 \mathrm{~h}$ was slow, but thereafter the rate of rehydration increased (Fig. 1). Indeed, high correlation coefficient of Pearson ( $r=0.995)$ was determined for the changes in RWC upon rehydration of both groups of plants. Some differences were observed after 9-24 h of rehydration, when the RWC values of leaves recovering after freezing-induced desiccation (RAF) were higher than those of leaves recovering after drought stress (RAD). RWC reached 14 and $22 \%$ after $15 \mathrm{~h}$ of rehydration of RAD and RAF plants, respectively, but it increased up to 45 and $70 \%$ after $24 \mathrm{~h}$. There were no significant differences in RWC of both plant groups after $7 \mathrm{~d}$ of rehydration, when they reached the usual water content of completely rehydrated plants $(90 \%)$.

Pigment content: Being homoiochlorophyllous resurrection plant, H. rhodopensis preserves most of its Chl content both during desiccation and rehydration. Some reduction in the Chl content of RAD plants was observed during the first $24 \mathrm{~h}$ of rehydration (Fig. $2 A$ ). The Chl content of dry RAF plants $(0 \mathrm{~h})$ was lower compared to dry RAD plants but upon rehydration their $\mathrm{Chl}$ content started increasing after $7 \mathrm{~h}$ of rehydration. Similar changes were detected for the carotenoid content in both plant groups during rewatering (Fig. 2B).
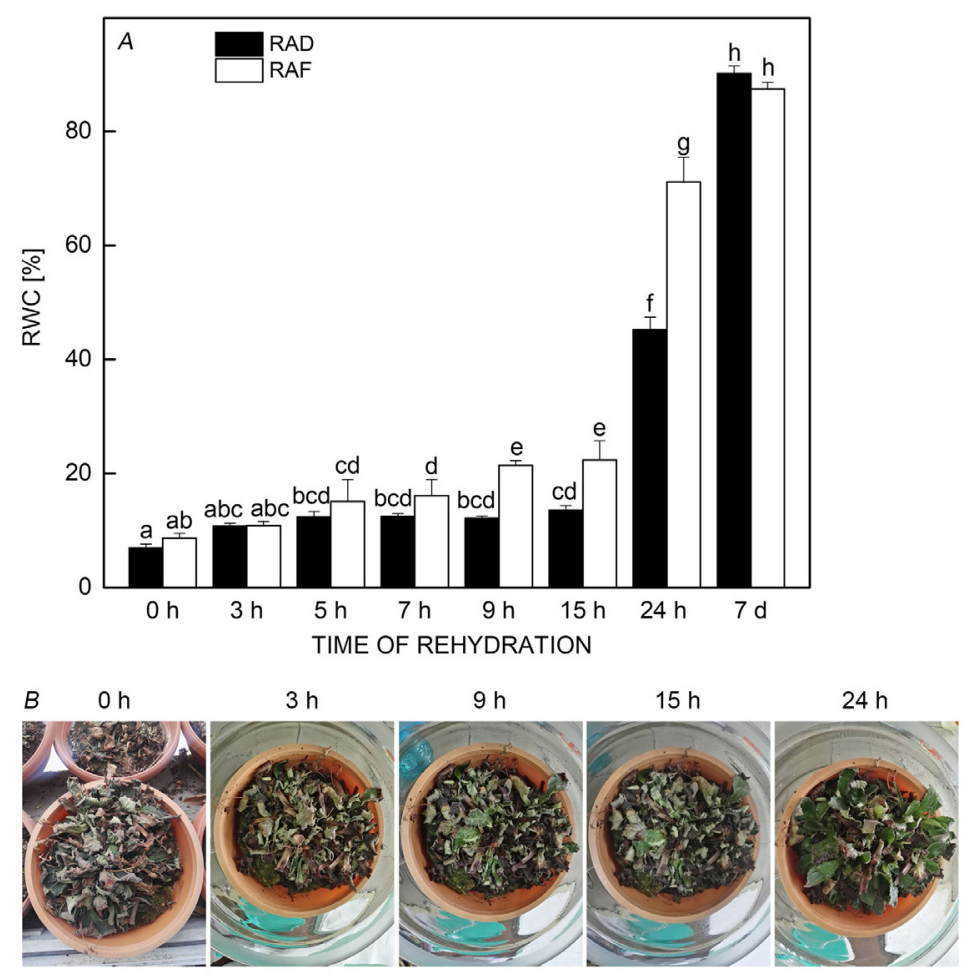

Chl $\boldsymbol{a}$ fluorescence: Upon rehydration, the maximum quantum efficiency of PSII photochemistry, estimated by the ratio $F_{v} / F_{m}$, gradually increased but it was statistically significant after $7 \mathrm{~h}$ of rehydration in both plant groups (Fig. 3). In agreement with the higher RWC, the values of $\mathrm{F}_{\mathrm{v}} / \mathrm{F}_{\mathrm{m}}$ measured after 9 and $15 \mathrm{~h}$ of rehydration were higher in RAF plants. A significant enhancement of $F_{v} / F_{m}$ was detected after $24 \mathrm{~h}$ of rehydration, reaching the values typical for fully hydrated plants after $7 \mathrm{~d}$ of rehydration. It should be mentioned that there were no differences in quantum efficiency of PSII between both plant groups after $24 \mathrm{~h}$ and $7 \mathrm{~d}$ of rehydration. The changes in the fractions of light absorbed by PSII antennae allocated to PSII photochemistry and thus photosynthetic electron transport, $\Phi_{\text {PSII }}$ (dark grey), thermal energy dissipation, $1-\mathrm{F}_{\mathrm{v}}{ }^{\prime} / \mathrm{F}_{\mathrm{m}}$ ' (light grey) and 'excess' energy, which was neither utilized in photosynthetic electron transport nor thermally dissipated, $\mathrm{F}_{\mathrm{v}}{ }^{\prime} / \mathrm{F}_{\mathrm{m}}{ }^{\prime} \times\left(1-\mathrm{q}_{\mathrm{P}}\right)$ (grey) during rehydration of plants are presented in Fig. 4. In contrast to $\mathrm{F}_{\mathrm{v}} / \mathrm{F}_{\mathrm{m}}$, the quantum yield of PSII electron transport $\left(\Phi_{\mathrm{PSII}}\right)$ recovered more slowly in the course of rehydration. The changes in $\Phi_{\text {PSII }}$ confirmed the faster recovery of RAF plants. Our results show that a significant enhancement in the photochemical activity of PSII of RAF plants was observed after $9 \mathrm{~h}$ of rehydration, when the values of $\Phi_{\text {PSII }}$ increased up to $25 \%$ of the level of completely rehydrated plants. The electron transport through PSII of RAD plants sharply increased after $24 \mathrm{~h}$ of rehydration. In fact, the extent of recovery of $\Phi_{\text {PSII }}$ in both plant groups after $24 \mathrm{~h}$ of rehydration was similar.

The low photochemical activity of PSII during the first $7 \mathrm{~h}$ of rehydration (Fig. 4) was accompanied by an increased amount of closed PSII reaction centers, estimated
Fig. 1. Changes in relative water content (RWC) after rehydration of Haberlea rhodopensis plants from drought- (RAD) and freezing-induced (RAF) desiccation $(A)$ and plants appearance after rehydration of RAF plants $(B)$. The error bars show SE and data represent the mean of $n=6$; the same letters within a graph indicate no significant differences assessed by Fisher's LSD test $(P \leq 0.05)$ after performing ANOVA. 


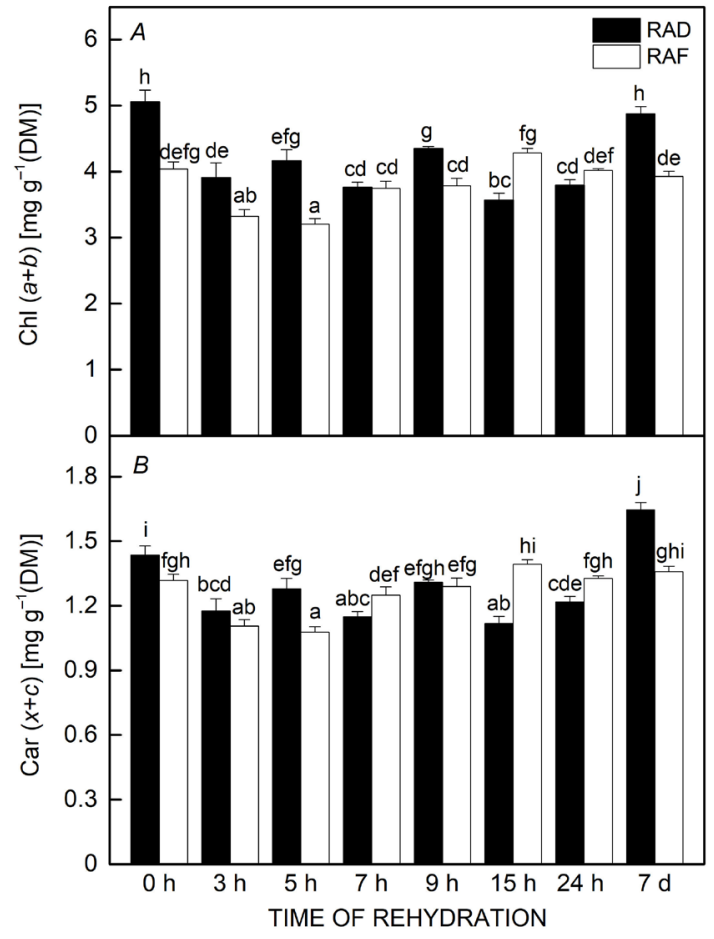

Fig. 2. Changes in leaf chlorophyll $[\mathrm{Chl}(a+b)](A)$ and carotenoid [Car $(x+c)](B)$ content after 3, 5, 7, 9, 15 and $24 \mathrm{~h}$, and after $7 \mathrm{~d}$ of rehydration of Haberlea rhodopensis plants from drought(RAD) and freezing-induced (RAF) desiccation. The error bars show SE and data represent the mean of $n=6$; the same letters within a graph indicate no significant differences assessed by Fisher's LSD test $(P \leq 0.05)$ after performing ANOVA.

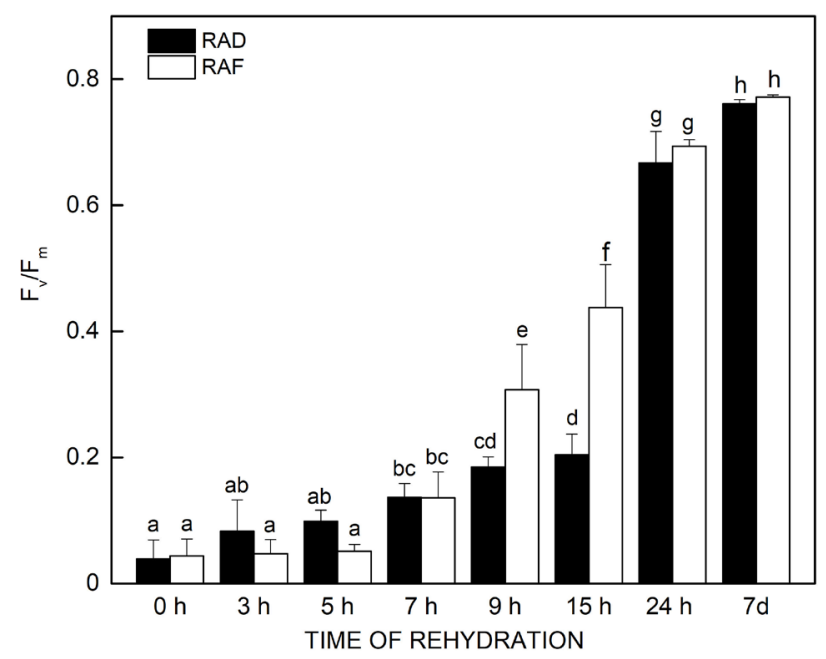

Fig. 3. Maximum quantum yield of PSII photochemistry in the dark-adapted state, $F_{\mathrm{v}} / \mathrm{F}_{\mathrm{m}}$ of rehydrated $(3,5,7,9,15$ and $24 \mathrm{~h}$, and $7 \mathrm{~d}$ ) Haberlea rhodopensis plants from drought- (RAD) and freezing-induced (RAF) desiccation. The error bars show SE and data represent the mean of $n=6$; the same letters within a graph indicate no significant differences assessed by Fisher's LSD test $(P \leq 0.05)$ after performing ANOVA. by the changes in $1-\mathrm{q}_{\mathrm{p}}$ or so-called excitation pressure (Fig. 5). Statistically significant reduction in the values of $1-\mathrm{q}_{\mathrm{P}}$ was observed after $7 \mathrm{~h}$, reaching the lowest values after $7 \mathrm{~d}$ of rehydration in both plant groups. Excitation pressure declined stronger in RAF plants compared to the RAD plants in the period 9-24 h of rehydration, which was in agreement with their higher PSII efficiency. A sharp reduction in excitation pressure was observed after $24 \mathrm{~h}$ of rehydration and the values in both plant groups after $7 \mathrm{~d}$ of rehydration were close to those for fully hydrated plants. In fact, high negative correlation coefficient of Pearson was determined for the rehydration-induced changes in the quantum yield of PSII electron transport and excitation pressure in both plant groups $(r=-0.993$ and $r=-0.965$ for RAD and RAF plants, respectively; $P \leq 0.05$ ).

Excitation pressure has been suggested to be a major prerequisite for the induction of efficient dissipation of the excess excitation energy thus protecting the PSII reaction center from over excitation. Indeed, the results showed that the fraction of light absorbed in PSII antennae, which is deactivated via thermal energy dissipation in the antennae, estimated as $1-\mathrm{F}_{\mathrm{v}}{ }^{\prime} / \mathrm{F}_{\mathrm{m}}{ }^{\prime}$, was high at the first hours of

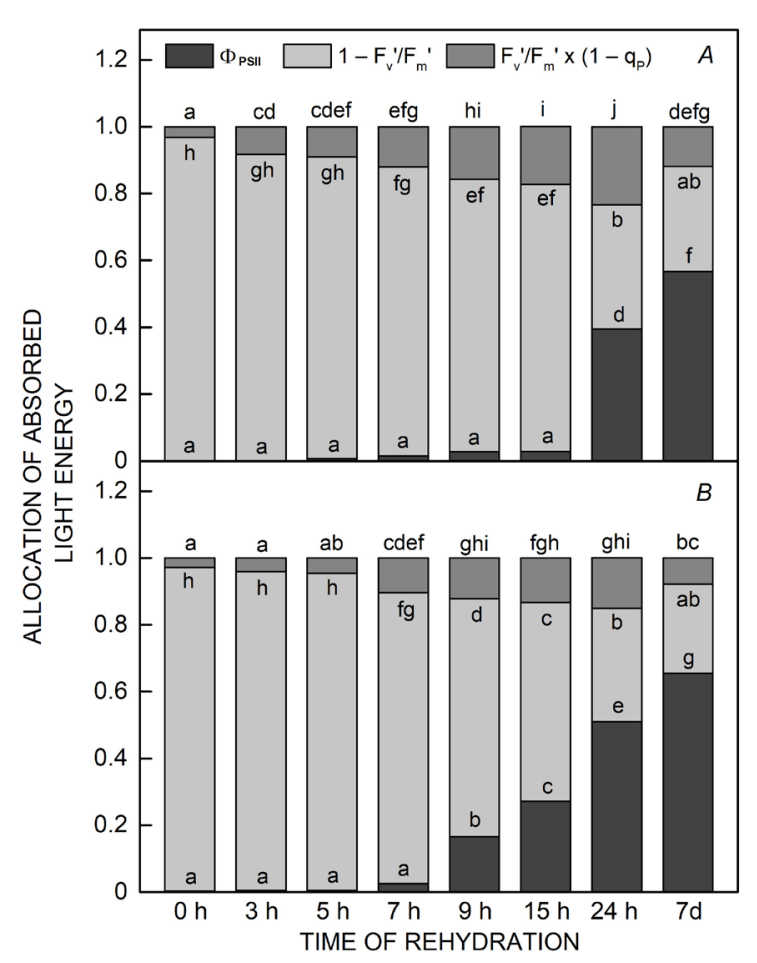

Fig. 4. Allocation of light absorbed by the PSII antennae to PSII photochemistry and thus photosynthetic electron transport, $\Phi_{\mathrm{PSI}}$ (dark grey), thermal energy dissipation, $1-\mathrm{F}_{\mathrm{v}}{ }^{\prime} / \mathrm{F}_{\mathrm{m}}{ }^{\prime}$ (light grey), and 'excess' energy, which represents a fraction of the absorbed light that was neither utilized in photosynthetic electron transport nor thermally dissipated, $\mathrm{F}_{\mathrm{v}}{ }^{\prime} / \mathrm{F}_{\mathrm{m}}{ }^{\prime} \times\left(1-\mathrm{q}_{\mathrm{p}}\right)($ grey) in Haberlea rhodopensis plants rehydrated from drought - $(\mathrm{RAD}, A)$ and freezing-induced (RAF, $B$ ) desiccation. The data represent the mean of $n=6$; the same letters within a graph indicate no significant differences assessed by Fisher's LSD test $(P \leq 0.05)$ after performing ANOVA. 
rehydration and it started declining after $7 \mathrm{~h}$ (Fig. 4, light grey). The values of $1-\mathrm{F}_{\mathrm{v}}{ }^{\prime} / \mathrm{F}_{\mathrm{m}}{ }^{\prime}$ were higher in RAD plants after $9-15 \mathrm{~h}$ of rehydration and were similar to those in RAF plants after $24 \mathrm{~h}$ and $7 \mathrm{~d}$. Actually, high correlation coefficient of Pearson was determined for the rehydrationinduced changes in the excitation pressure and thermal energy dissipation in both plant groups $(r=0.990$ and $r=0.982$ for RAD and RAF plants, respectively; $P \leq 0.05$ ).

The levels of excess light that is not going into either photosynthetic electron transport or thermal dissipation, $\mathrm{F}_{\mathrm{v}}{ }^{\prime} / \mathrm{F}_{\mathrm{m}}{ }^{\prime} \times\left(1-\mathrm{q}_{\mathrm{P}}\right)$, gradually increased during rehydration of both RAD and RAF plants, reaching maximum after $24 \mathrm{~h}$ (Fig. 4, grey). Then the values of $\mathrm{F}_{\mathrm{v}}{ }^{\prime} / \mathrm{F}_{\mathrm{m}}{ }^{\prime} \times\left(1-\mathrm{q}_{\mathrm{P}}\right)$ significantly decreased in completely rehydrated plants.

$\mathbf{P}_{700}$ : The increase in leaf absorption in the 820-nm region $\left(\triangle \mathrm{A}_{820}\right)$ after far-red irradiance reflected increased PSI activity which was accompanied with increased oxidized form of PSI reaction center $\mathrm{P}_{700}{ }^{+}$. Following rehydration, PSI activity recovered faster compared to PSII (Fig. 6). Surprisingly, in contrast to PSII, better recovery of PSI activity was observed in RAD plants compared to RAF ones. PSI reached maximum activity after 15 and $24 \mathrm{~h}$ of rehydration of RAF and RAD plants, respectively.

77 K fluorescence: In the present study we analyzed the changes in $77 \mathrm{~K}$ fluorescence spectra of isolated thylakoid membranes from RAD and RAF $H$. rhodopensis plants. Fluorescence spectra at low temperature $(77 \mathrm{~K})$ of isolated thylakoid membranes are characterized by emission bands at 685 and a shoulder at $695 \mathrm{~nm}$, emitted by the complex of PSII and a band at $735 \mathrm{~nm}$ emitted by PSI (Krause and Weis 1991, Andrizhiyevskaya et al. 2005). The intensities of these bands depend on the populations of both photosystems, energy delivery to them and on the spillover

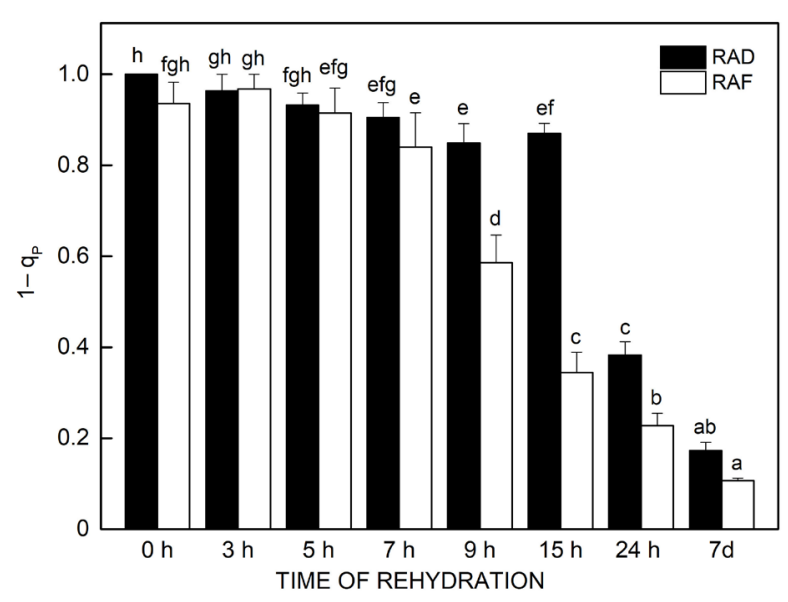

Fig. 5. Changes in excitation pressure, $1-\mathrm{q}_{\mathrm{p}}$ measured in rehydrated $(3,5,7,9,15$, and $24 \mathrm{~h}$, and $7 \mathrm{~d})$ Haberlea rhodopensis plants from drought- (RAD) and freezing-induced (RAF) desiccation. The error bars show SE and data represent the mean of $n=6$; the same letters within a graph indicate no significant differences assessed by Fisher's LSD test $(P \leq 0.05)$ after performing $A N O V A$. of excited energy from PSII to PSI. On the base of analysis of emission spectra, the ratios of intensities of fluorescence bands at 685, 695, and $735 \mathrm{~nm}$ were calculated and presented (Fig. 7). The participation of different $\mathrm{Chl}$ pools in energy supply of both photosystems was estimated analyzing the excitation spectra of fluorescence at $735 \mathrm{~nm}$ (emitted by PSI) and at $685 \mathrm{~nm}$ (emitted by PSII) (Fig. 8).

The rehydration-induced alterations in the fluorescence ratio $\mathrm{F}_{735} / \mathrm{F}_{685}$ at excitation with $436 \mathrm{~nm}$ (exciting preferably $\mathrm{Chl} a$ ) are presented in Fig. $7 A$. The first $7 \mathrm{~h}$ of rehydration led to significant changes in the ratio $F_{735} / F_{685}$. Although the value for $\mathrm{F}_{735} / \mathrm{F}_{685}$ was lower for RAD (1.35) than that for RAF (1.42) in fully desiccated plants, for RAD plants, it changed more considerably reaching a value of 1.7 after $3 \mathrm{~h}$ of rehydration. After $7 \mathrm{~h}$ of rehydration the values for both samples were very close but after $7 \mathrm{~d}$ (fully rehydrated plants), $\mathrm{F}_{735} / \mathrm{F}_{685}$ ratio for RAD plants was higher than that for RAF.

Changes of ratio $\mathrm{F}_{685} / \mathrm{F}_{695}$ (Fig. $7 B$ ) characterize alteration of energy interaction within PSII complexes as the peak at $685 \mathrm{~nm}$ is believed to be emitted by PSII core complex and the shoulder at $695 \mathrm{~nm}$ by CP47 (Andrizhiyevskaya et al. 2005). During the first 3-7 h of rehydration, a decrease of $\mathrm{F}_{685} / \mathrm{F}_{695}$ was detected for both types of rehydrated plants - RAD and RAF.

In order to estimate any changes in the antenna complexes and energy supply of both photosystems, the excitation spectra of fluorescence emitted by the complexes of PSI $(735 \mathrm{~nm})$ and PSII (685 nm) were analyzed in the 'red' (700-610 nm) and 'blue' (500-410 nm) region, respectively. The values of $\mathrm{E}_{680} / \mathrm{E}_{650}$ (excitation of PSI) for thylakoid membranes isolated from RAF plants were higher than that for RAD plants for all presented samples

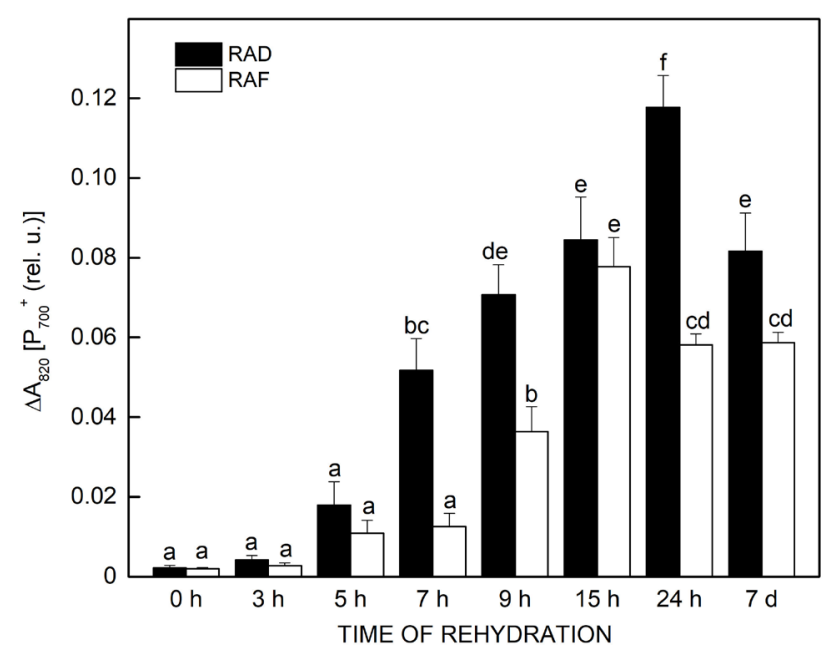

Fig. 6. Photochemical activity of PSI, evaluated by leaf absorbtion changes at $\Delta \mathrm{A}_{820}$ after far-red illumination, after 3, 5, $7,9,15$, and $24 \mathrm{~h}$, and after $7 \mathrm{~d}$ of rehydration of Haberlea rhodopensis plants from drought- (RAD) and freezing-induced (RAF) desiccation. The error bars show SE and data represent the mean of $n=6$; the same letters within a graph indicate no significant differences assessed by Fisher's LSD test $(P \leq 0.05)$ after performing $A N O V A$. 
except for those hydrated for $7 \mathrm{~d}$. For thylakoid membranes isolated from both groups of plants (RAD and RAF), a decrease of ratio $\mathrm{E}_{680} / \mathrm{E}_{650}$ was observed in the first $3 \mathrm{~h}$ of rehydration thus indicating an increase in involvement of $\mathrm{Chl} b$ molecules in comparison to $\mathrm{Chl} a$ in energy supply of PSI (Fig. 8A). At the same time period for RAD plants, an increase of $\mathrm{E}_{470} / \mathrm{E}_{436}$ was observed for emission at $685 \mathrm{~nm}$ demonstrating an enhanced participation of $\mathrm{Chl} b$ in energy delivery to PSII (Fig. 8B). However, in the first 3-7 h, a decrease of $\mathrm{E}_{470} / \mathrm{E}_{436}$ for emission at $685 \mathrm{~nm}$ was observed for RAF plants in contrast to RAD plants, thus showing different rearrangement of PSII and its antenna after rehydration of plants subjected to freezing-induced water deficit in comparison with desiccation induced by drought.

\section{Discussion}

In order to survive desiccation to air-dry state and to completely recover functional activity after rehydration, the homoiochlorophyllous resurrection plants have to preserve the integrity of photosynthetic apparatus upon desiccation. In order to reach this goal, plants have developed different mechanisms not only for diminishing damages suffered during severe water loss but during rehydration as well. It

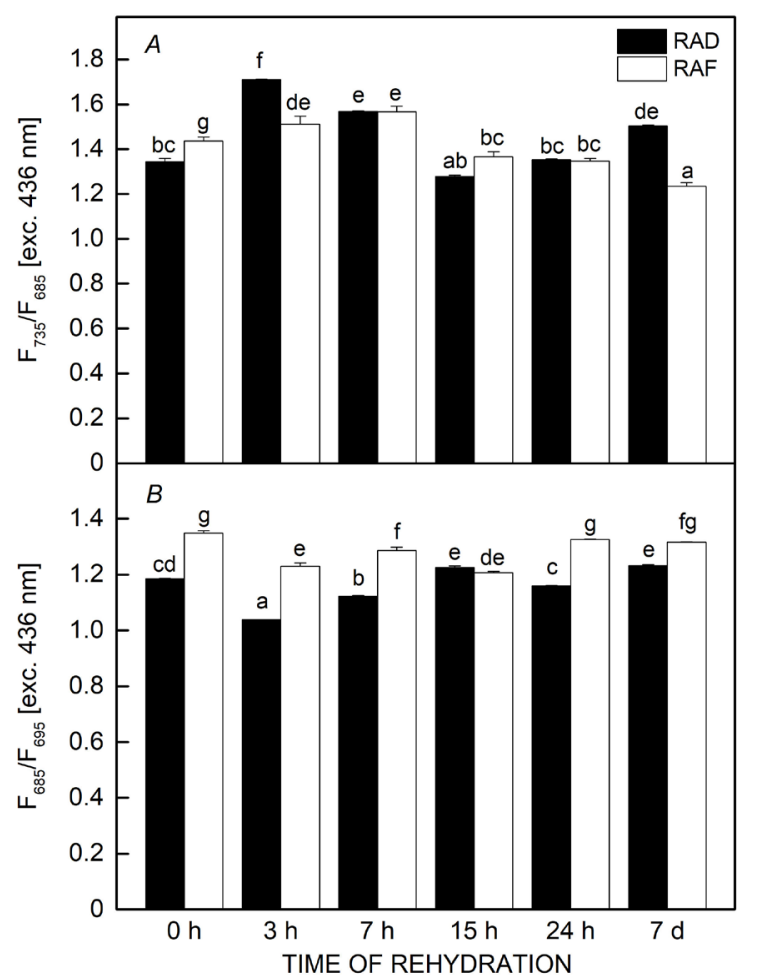

Fig. 7. Changes in the ratios of intensities of fluorescence bands at 735 and $685 \mathrm{~nm}, \mathrm{~F}_{735} / \mathrm{F}_{685}(A)$ and 685 and $695 \mathrm{~nm}, \mathrm{~F}_{685} / \mathrm{F}_{695}(B)$ after 3, 7, 15 and $24 \mathrm{~h}$, and after $7 \mathrm{~d}$ of rehydration of Haberlea rhodopensis plants from drought- (RAD) and freezing-induced (RAF) desiccation. The error bars show SE and data represent the mean of $n=6$; the same letters within a graph indicate no significant differences assessed by Fisher's LSD test $(P \leq 0.05)$ after performing ANOVA. has been demonstrated that if the protective mechanisms during desiccation are hampered or inadequate then the importance of protective mechanisms at increased water availability is crucial for achieving plant vitality (Cooper and Farrant 2002).

In the present study, we investigated the recovery of photosynthetic activity after rehydration of Haberlea rhodopensis from air-dry state induced by drought or freezing stress for better understanding the strategies for survival of this resurrection plant. The results show that water uptake during the initial $15 \mathrm{~h}$ was slow, which could be considered as an adaptive defense mechanism to avoid cellular damages by a rapid water uptake upon rehydration. The plants increase their water content faster after $24 \mathrm{~h}$ of rehydration. Hence, the kinetics of recovery of RAD and RAF plants was similar and consists of two phases - slow and rapid. The investigations on recovery of resurrection plants after the onset of rewatering were performed mainly with genus Ramonda, close relative of Haberlea rhodopensis (Gesneriaceae). According to Rakić et al. (2014), at the beginning of rehydration, the recovering plant goes through an oscillatory, unstable, and vulnerable short period. The plant regains satisfactory stability in about $48 \mathrm{~h}$ but complete repair could be seen

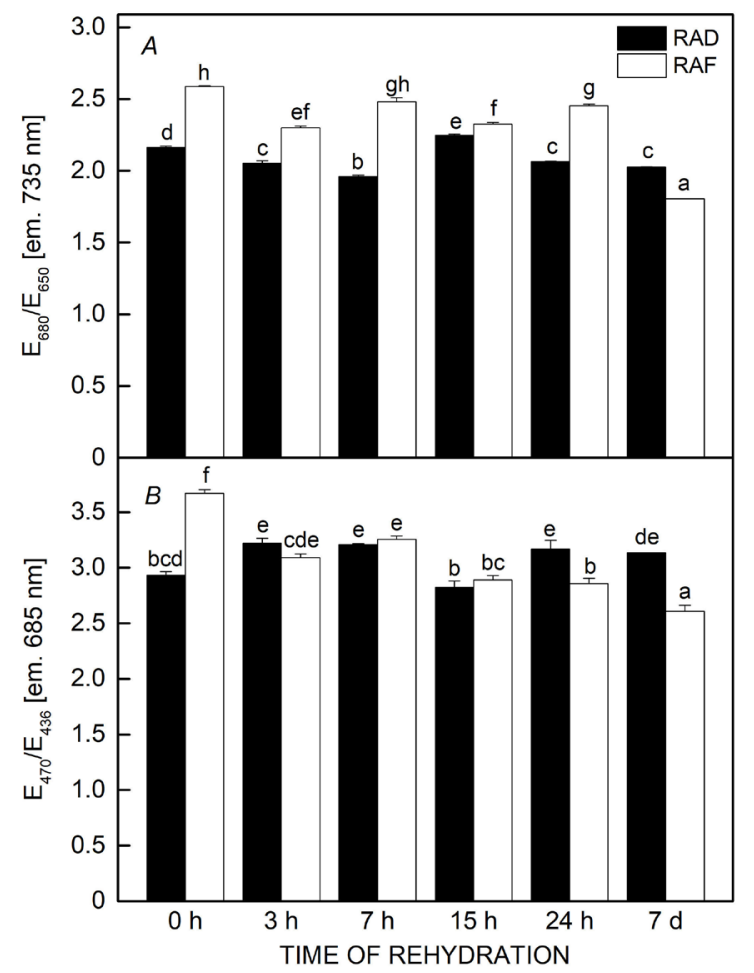

Fig. 8. Changes in the ratio of intensities of bands at 680 and $650 \mathrm{~nm}$ in excitation spectra of fluorescence emitted at $735 \mathrm{~nm}$, $\mathrm{E}_{680} / \mathrm{E}_{650}(A)$ and 470 and $436 \mathrm{~nm}$ in the excitation spectra of fluorescence emitted at $685 \mathrm{~nm}, \mathrm{E}_{470} / \mathrm{E}_{436}(B)$ after 3, 7, 15, and $24 \mathrm{~h}$, and after $7 \mathrm{~d}$ of rehydration of Haberlea rhodopensis plants from drought- (RAD) and freezing-induced (RAF) desiccation. The error bars show SE and data represent the mean of $n=6$; the same letters within a graph indicate no significant differences assessed by Fisher's LSD test $(P \leq 0.05)$ after performing ANOVA. 
after 6 d of rehydration. Živković et al. (2005) showed that rehydration of desiccated Ramonda serbica for $6 \mathrm{~h}$ and $24 \mathrm{~h}$ increased their RWC up to 23 and $45 \%$, respectively, which was similar to our results with RAD plants. However, the extent of increase of RWC during rehydration of dry plants varies in different studies even for the same plant species (Jovanović et al. 2011, Gashi et al. 2013). The time of recovery depends on plant size and age, method of rehydration, drying rate, desiccation extent, and duration before rehydration (Farrant et al. 1999, Farrant 2007). Gashi et al. (2013) demonstrated that the RWC was restored more rapidly in Ramonda nathaliae than in Ramonda serbica reaching 70 and $30 \%$, respectively, after $6 \mathrm{~h}$ of rehydration. In addition, Tan et al. (2017) showed that completely dried plants Boea hygrometrica restored their RWC very fast upon rehydration reaching 50 and $95 \%$ RWC within only 12 and $24 \mathrm{~h}$, respectively. Most probably, this rapid recovery was due to plant age since four-month-old plants propagated from seeds were used in the experiments. Very fast restoration of RWC was also observed after rehydration of in vitro propagated H. rhodopensis (Djilianov et al. 2011). Plants regain 56\% of their RWC after $1-3 \mathrm{~h}$ of rewatering. In vitro propagated plants are small and it is well known that younger leaves restore their RWC faster. Our results show faster recovery of RAF compared to RAD H. rhodopensis plants which could be due to different environmental conditions during desiccation. In fact, previous studies on $H$. rhodopensis showed that the water uptake and the recovery of the roots were faster than leaves upon rewetting (Péli et al. 2012).

Significant enhancement in PSII activity was observed when RWC reached $20 \%$. The results showed faster recovery of quantum efficiency of PSII in RAF plants and the most significant differences between RAD and RAF plants were evident after $9-15 \mathrm{~h}$ of rehydration. The lower photochemical activity of PSII in RAD plants may be due to their lower water content and higher amount of closed PSII reaction centers. The studies on $R$. serbica showed that the intrinsic PSII efficiency remained at very low levels even when RWC recovered to 36\% (Degl'Innocenti et al. 2008). After that, a slight increase was observed for $50 \%$ RWC, but $\mathrm{CO}_{2}$ fixation rate did not restore at this time point of rehydration. Our previous studies also revealed that during rehydration the $\mathrm{CO}_{2}$ assimilation slowly increased, but reached positive values after $72 \mathrm{~h}$ of rehydration, when the water content recovered to the values of controls (Péli et al. 2012). In agreement with lower photochemical activity of PSII, the excitation pressure on open PSII reaction centers was significantly higher in RAD compared to RAF $H$. rhodopensis plants during the first $9-15 \mathrm{~h}$ after rewatering. Thus, it is obvious that the early stage of rehydration is potentially harmful for PSII reaction centers, because of low RWC, low electron transport capacity, and high excitation pressure. Under conditions of high excitation pressure, energy balance can be reestablished by diminishing the light-harvesting antenna size or increased energy dissipation as heat with no change in the absolute antenna size (Hüner et al. 2003).

It was found that in desiccated state and during the first hours of rehydration, most of the light absorbed in PSII antennae was allocated to thermal energy dissipation, protecting plants against photooxidation when photosynthetic activity was still not recovered. Another mechanism of thermal energy dissipation was proposed to be activated during desiccation of poikilohydric autotrophs (Heber and Shuvalov 2005, Heber et al. 2006a). Loss of water during desiccation in combination with the reduction of $\mathrm{Q}_{\mathrm{A}}$ appears to change the conformation of PSII reaction centers so as to transform them from energy-conserving to energy-dissipating centers (Heber et al. 2006a, Heber 2008). The role of this additional photoprotective mechanism within PSII reaction centers have been reported for several desiccation tolerant mosses, lichens, and ferns (Heber et al. 2006a,b, 2007; Heber 2008, Flores-Bavestrello et al. 2016). Our results showed that during rehydration, the 'excess' energy, which was neither utilized in photosynthetic electron transport nor thermally dissipated, gradually increased. The 'excess' energy reflects energy quenching processes occurring within PSII reaction center with $\mathrm{Q}_{\mathrm{A}}$ in a reduced state, indicating the role of PSII reaction center quenching during the recovery after rehydration.

The results from fluorescence excitation spectra suggest that during rehydration the size of the light harvesting antenna of PSI does not change significantly for RAD and RAF plants. However, different behavior was observed for PSII complexes - for RAF plants, the involvement of $\mathrm{Chl} b$ in energy supply of PSII in comparison with Chl $a$ decreased gradually with the time of rehydration. High excitation pressure at the beginning of rehydration was accompanied by a corresponding increase of proportion of thermal energy dissipation in the antenna $\left(1-\mathrm{F}_{\mathrm{v}}{ }^{\prime} / \mathrm{F}_{\mathrm{m}}{ }^{\prime}\right)$, suggesting its protective effect in severely desiccated plants.

The most prominent alterations in energy transfer and interaction between the main photosynthetic pigment protein complexes as evidenced by $77 \mathrm{~K}$ fluorescence emission spectra were observed during the first hours ( 3 and $7 \mathrm{~h}$ ) of rehydration. The contours of fluorescence spectra of thylakoid membranes isolated from RAD and RAF were not altered in respect to positions of the main peaks but their relative intensities were changed. The ratio of $\mathrm{F}_{735} / \mathrm{F}_{685}$ increased during the first 3-7 h of rehydration that was valid for both groups of plants, stronger expressed for the $3^{\text {th }}$ hour. The observed increase in $\mathrm{F}_{735} / \mathrm{F}_{685}$ ratio could occur due to two reasons. First, as a result of desiccationinduced unstacking of thylakoid membranes more energy is transferred to and emitted by the PSI complex $\left(\mathrm{F}_{735}\right)$. Second, a decrease of the emission from PSII $\left(\mathrm{F}_{685}\right)$ could be related to a reduction of the population of PSII complexes (Charuvi et al. 2015) and/or fluorescence quenching by inactivated complexes of PSII (Hundal et al. 1990, Velitchkova and Popova 2005, Popova et al. 2019). It had been shown that in thylakoids and PSII particles, inactivation of the donor side of PSII is accompanied by a formation of a $\mathrm{P}_{685}{ }^{+}$, a quencher of the fluorescence emitted by PSII reaction center (Horton and Ruban 1992, Bruce et al. 1997). The suggestion that the elevated $\mathrm{F}_{735} / \mathrm{F}_{685}$ ratio after $3 \mathrm{~h}$ of rehydration is related to quenching of fluorescence is supported by the decrease 
of the ratio of $\mathrm{F}_{685} / \mathrm{F}_{695}$.

Moreover, the faster enhancement in $\mathrm{F}_{\mathrm{v}} / \mathrm{F}_{\mathrm{m}}$ values compared to $\Phi_{\mathrm{PSII}}$ at the beginning of rehydration, when $\mathrm{CO}_{2}$ assimilation was still negative (Péli et al. 2012), can create an energy imbalance between the primary and secondary reactions of photosynthesis, which was confirmed by high excitation pressure under these conditions. This, in turn, can potentially result in generation of reactive oxygen species. Indeed, increased activity of superoxide dismutase, ascorbate peroxidase, catalase, glutathione reductase, and nonspecific peroxidases was detected, indicating that the first few hours of rehydration represent extremely dramatic period regarding oxidative stress (Sgherri et al. 2004, Jovanović et al. 2011). On the other hand, the elevated contents of phenols during the first phase of rehydration suggest that they also might have a role in scavenging of ROS (Sgherri et al. 2004). The importance of the first few hours of rehydration for plants recovery was also shown by studies of Bernacchia et al. (1996) during the rehydration process of dried Craterostigma plantagineum plants. It was found that the dehydration-specific gene products disappeared during an early phase of rehydration (within $6 \mathrm{~h}$ after the contact with water), a small number of rehydration-specific transcripts was synthesized around 12 to $15 \mathrm{~h}$ after the onset of rewatering and hydration-related gene products appeared concomitantly.

Following rehydration, PSI activity recovered faster compared to PSII and in contrast to PSII, its activity was higher in RAD compared to RAF plants. Another feature upon recovery of the activity of this photosystem is the restoration of maximum activity after 15 and $24 \mathrm{~h}$ of rehydration of RAF and RAD plants, respectively, when PSII activity significantly increased. In fact, our previous results showed the higher PSI activity in moderately dehydrated $H$. rhodopensis plants compared to wellhydrated plants (Georgieva et al. 2005). In recent years, a number of alternative pathways for photosynthetic electron transport, including PSI-dependent cyclic electron flow, the chlororespiratory pathway mediated by a chloroplastic $\mathrm{NAD}(\mathrm{P}) \mathrm{H}$ dehydrogenase that uses stromal $\mathrm{NAD}(\mathrm{P}) \mathrm{H}$ for the nonphotochemical reduction of $\mathrm{PQ}$ to $\mathrm{PQH}_{2}$ and the terminal plastoquinol oxidase (PTOX)-mediated electron flow to $\mathrm{O}_{2}$ have been heavily implicated to play a critical role in protecting the photosynthetic apparatus against various environmental stresses (Savitch et al. 2010, McDonald et al. 2011, Ivanov et al. 2012). In fact, the enhancement of PSI-dependent cyclic electron flow has been shown to improve the recovery of severely desiccated Porphyra yezoensis (Gao and Wang 2012).

The results of our study indicate that the photochemical activity of $H$. rhodopensis regain satisfactory stability after $24 \mathrm{~h}$ of rehydration and the differences in photochemical activity of RAD and RAF plants significantly decreased. The quantum efficiency of electron transport trough PSII was more than $70 \%$ of the control level, PSI activity was restored, the excitation pressure was significantly reduced and the proportion of thermal energy dissipation in the antenna was close to the fully rehydrated plants. These data are in agreement with our previous study on subcellular organization of mesophyll cells showing that after $1 \mathrm{~d}$ of rehydration the inner vacuoles seemed to enlarge, the organelles started to return to their normal position and by the end of the first day of rehydration, the plastids regained their half-lens shape at the plasmalemma (Georgieva et al. 2017b).

In summary, it could be concluded that the early stage of rehydration of desiccated to air-dry state Haberlea rhodopensis plants is potentially harmful and plants need adequate and effective protection during this period. The most significant differences in the recovery process of photosynthetic activity of RAD and RAF plants were observed after $9-15 \mathrm{~h}$ of rehydration. PSI activity recovered more rapidly and PSII activity more slowly in early hours of rehydration of RAD compared to RAF plants. The high thermal energy dissipation in dry plants and during the first hours of their rehydration protect them from photooxidation and the role of PSII reaction center quenching during the recovery period was suggested.

\section{References}

Andrizhiyevskaya E.G., Chojnicka A., Bautista J.A. et al.: Origin of the F685 and F695 fluorescence in Photosystem II. Photosynth. Res. 84: 173-180, 2005.

Benina M., Obata T., Mehterov N. et al.: Comparative metabolic profiling of Haberlea rhodopensis, Thellungiella halophyla, and Arabidopsis thaliana exposed to low temperature. Front. Plant Sci. 4: 499, 2013.

Bernacchia G., Salamini F., Bartels D.: Molecular characterization of the rehydration process in the resurrection plant Craterostigma plantagineum. - Plant Physiol. 111: 10431050, 1996.

Bewley J.D.: Physiological aspects of desiccation tolerance. Ann. Rev. Plant Physio. 30: 195-238, 1979.

Bewley J.D., Oliver M.J.: Desiccation tolerance in vegetative plant tissues and seeds: protein synthesis in relation to desiccation and a potential role for protection and repair mechanisms. In: Somero G.N., Osmond C.B., Bolis C.L. (ed.): Water and Life. Pp. 141-160. Springer, Berlin-Heidelberg 1992.

Bruce D., Samson G., Carpenter C.: The origins of nonphotochemical quenching of chlorophyll in photosynthesis. Direct quenching by $\mathrm{P} 680^{(+)}$in photosystem II enriched membranes at low pH. - Biochemistry-US 36: 749-755, 1997.

Charuvi D., Nevo R., Shimoni E. et al.: Photoprotection conferred by changes in photosynthetic protein levels and organization during dehydration of a homoiochlorophyllous resurrection plant. - Plant Physiol. 167: 1554-1565, 2015.

Cooper K., Farrant J.M.: Recovery of the resurrection plant Craterostigma wilmsii from desiccation: protection versus repair. - J. Exp. Bot. 53: 1805-1813, 2002.

Daskalova E., Dontcheva S., Yahoubian G. et al:: A strategy for conservation and investigation of the protected resurrection plant Haberlea rhodopensis Friv. - BioRisk 6: 41-60, 2011.

Daskalova E., Dontcheva S., Yahubyan G. et al.: Ecological characteristics and conservation of the protected resurrection species Haberlea rhodopensis Friv. as in vitro plants through a modified micropropagation system. - Biotechnol. Biotec. Eq. 24: 213-217, 2010.

Degl'Innocenti E., Guidi L., Stevanovic B., Navari F.: $\mathrm{CO}_{2}$ fixation and chlorophyll a fluorescence in leaves of Ramonda serbica during a dehydration-rehydration cycle. - J. Plant Physiol. 165: 723-733, 2008.

Demmig-Adams B., Adams III W.W., Barker D.H. et al.: Using chlorophyll fluorescence to assess the fraction of absorbed 
light allocated to thermal dissipation of excess excitation. Physiol. Plantarum 98: 253-264, 1996.

Deng X., Hu Z.A., Wang H.X. et al.: A comparison of photosynthetic apparatus of the detached leaves of the resurrection plant Boea hygrometrica with its non-tolerant relative Chirita heterotrichia in response to dehydration and rehydration. - Plant Sci. 165: 851-861, 2003.

Djilianov D., Ivanov S., Moyankova D. et al:: Sugar ratios, glutathione redox status and phenols in the resurrection species Haberlea rhodopensis and the closely related nonresurrection species Chirita eberhardtii. - Plant Biol. 13: 767-776, 2011.

Farrant J.M.: Mechanisms of desiccation tolerance in angiosperm resurrection plants. - In: Jenks M., Wood A. (ed.): Plant Desiccation Tolerance. Pp. 51-90. Blackwell Publishing, Wallingford 2007.

Farrant J.M., Brandt W.F., Lindsey G.G.: An overview of mechanisms of desiccation tolerance in selected angiosperm resurrection plants. - Plant Stress 1: 72-84, 2007.

Farrant J.M., Cooper K., Kruger L.A., Sherwin H.W.: The effect of drying rate on the survival of three desiccation-tolerant angiosperm species. - Ann. Bot.-London 84: 371-379, 1999.

Fernández-Marín B., Nadal M., Gago J. et al.: Born to revive: molecular and physiological mechanisms of double tolerance in a paleotropical and resurrection plant. - New Phytol. 226: 741-759, 2020

Fernández-Marín B., Neuner G., Kuprian E. et al.: First evidence of freezing tolerance in a resurrection plant: insights into molecular mobility and zeaxanthin synthesis in the dark. Physiol. Plantarum 163: 472-489, 2018.

Flores-Bavestrello A., Król M., Ivanov A.G. et al.: Two Hymenophyllaceae species from contrasting natural environments exhibit a homoiochlorophyllous strategy in response to desiccation stress. - J. Plant Physiol. 191: 82-94, 2016.

Gaff D.F., Oliver M.: The evolution of desiccation tolerance in angiosperm plants: a rare yet common phenomenon. - Funct. Plant Biol. 40: 315, 2013.

Gao S., Wang G.: The enhancement of cyclic electron flow around photosystem I improves the recovery of severely desiccated Porphyra yezoensis (Bangiales, Rhodophyta). J. Exp. Bot. 63: 4349-4358, 2012.

Gashi B., Babani F., Kongjika E.: Chlorophyll fluorescence imaging of photosynthetic activity and pigment contents of the resurrection plants Ramonda serbica and Ramonda nathaliae during dehydration and rehydration. - Physiol. Mol. Biol. Pla. 19: 333-341, 2013.

Gashi B., Kongjika E., Osmani M., Luma V.: Activity of $\delta$-aminolevulinic acid dehydratase at Ramonda nathaliae and Ramonda serbica plants during dehydration and rehydration. - Biol. Futur. 70: 210-217, 2019.

Genty B., Briantais J.M., Baker N.R.: The relationship between the quantum yield of photosynthetic electron transport and quenching of chlorophyll fluorescence. - BBA-Gen. Subjects 990: 87-92, 1989.

Georgieva K., Dagnon S., Gesheva E. et al:: Antioxidant defense during desiccation of the resurrection plant Haberlea rhodopensis. - Plant Physiol. Bioch. 114: 51-59, 2017 a.

Georgieva K., Maslenkova L., Peeva V. et al.: Comparative study on the changes in photosynthetic activity of the homoiochlorophyllous desiccation-tolerant Haberlea rhodopensis and desiccation-sensitive spinach leaves during desiccation and rehydration. - Photosynth. Res. 85: 191-203, 2005.

Georgieva K., Mihailova G.: Drought tolerance of photosynthesis. - In: Pessarakli M. (ed.): Handbook of Photosynthesis. $3^{\text {rd }}$ Edition. Pp. 683-695. CRC Press, Boca Raton 2016.
Georgieva K., Mihailova G., Gigova L. et al.: Freezing tolerance of resurrection plant Haberlea rhodopensis.- In: FEBS Advanced Courses - Resurrection Plants: Hope for Crop Drought Tolerance (ReHOPE) (Abstract Book). Pp. 13. 20-22 September, Plovdiv, Bulgaria 2018. https://rehope2018. febsevents.org/

Georgieva K., Rapparini F., Bertazza G. et al.: Alterations in the sugar metabolism and in the vacuolar system of mesophyll cells contribute to the desiccation tolerance of Haberlea rhodopensis ecotypes. - Protoplasma 254: 193-201, 2017 b.

Georgieva K., Röding A., Büchel C.: Changes in some thylakoid membrane proteins and pigments upon desiccation of the resurrection plant Haberlea rhodopensis. - J. Plant Physiol. 166: 1520-1528, 2009.

Georgieva K., Szigeti Z., Sarvari E. et al.: Photosynthetic activity of homoiochlorophyllous desiccation tolerant plant Haberlea rhodopensis during dehydration and rehydration. - Planta 225: 955-964, 2007.

Giarola V., Bartels D.: What can we learn from the transcriptome of the resurrection plant Craterostigma plantagineum? Planta 242: 427-434, 2015.

Giarola V., Hou Q., Bartels D.: Angiosperm plant desiccation tolerance: hints from transcriptomics and genome sequencing.Trends Plant Sci. 22: 705-717, 2017.

Heber U.: Photoprotection of green plants: a mechanism of ultra-fast thermal energy dissipation in desiccated lichens. Planta 228: 641-650, 2008.

Heber U., Azarkovich M., Shuvalov V.: Activation of mechanisms of photoprotection by desiccation and by light: poikilohydric photoautotrophs. - J. Exp. Bot. 58: 2745-2759, 2007.

Heber U., Bilger W., Shuvalov V.A.: Thermal energy dissipation in reaction centres and in the antenna of photosystem II protects desiccated poikilohydric mosses against photooxidation. - J. Exp. Bot. 57: 2993-3006, 2006b.

Heber U., Lange O.L., Shuvalov V.A.: Conservation and dissipation of light energy as complementary processes: homoiohydric and poikilohydric autotrophs. - J. Exp. Bot. 57: 1211-1223, 2006a.

Heber U., Shuvalov V.A.: Photochemical reactions of chlorophyll in dehydrated photosystem II: two chlorophyll forms (680 and $700 \mathrm{~nm}$ ). - Photosynth. Res. 84: 85-91, 2005.

Horton P., Ruban A.: Regulation of Photosystem II. - Photosynth. Res. 34: 375-385, 1992.

Huang W., Yang S.J., Zhang S.B. et al.: Cyclic electron flow plays an important role in photoprotection for the resurrection plant Paraboea rufescens under drought stress. - Planta 235: 819-828, 2012.

Hundal T., Virgin I., Styring S., Andersson B.: Changes in the organization of photosystem II following light-induced D1-protein degradation. - BBA-Bioenergetics 1017: 235241, 1990.

Hüner N.P., Öquist G., Melis A.: Photostasis in plants, green algae and cyanobacteria: the role of light harvesting antenna complexes. - In: Green B.R., Parson W.W. (ed.): Light-Harvesting Antennas in Photosynthesis. Advances in Photosynthesis and Respiration. Vol. 13. Pp. 401-421. Springer, Dordrecht 2003.

Ivanov A.G., Rosso D., Savitch L.V. et al.: Implications of alternative electron sinks in increased resistance of PSII and PSI photochemistry to high light stress in cold acclimated Arabidopsis thaliana. - Photosynth. Res. 113: 191-206, 2012.

Jovanović Ž., Rakić T., Stevanović B., Radović S.: Characterization of oxidative and antioxidative events during dehydration and rehydration of resurrection plant Ramonda nathaliae. - Plant Growth Regul. 64: 231-240, 2011.

Kappen L.: [The influence of water content on the resistance 
of plants to high and low temperatures, examined on leaves of some ferns and Ramonda myconi.] - Flora 156: 427-445, 1966. https://doi.org/10.1016/S0367-1836(17)30278-1 [In German]

Krause G.H., Weis E.: Chlorophyll fluorescence and photosynthesis. The basics. - Annu. Rev. Plant Phys. 42: 313-349, 1991.

Lawlor D.W., Cornic G.: Photosynthetic carbon assimilation and associated metabolism in relation to water deficits in higher plants. - Plant Cell Environ. 25: 275-294, 2002.

Lichtenthaler H.K.: Chlorophylls and carotenoids: pigments of photosynthetic biomembranes. - Method. Enzymol. 148: 350382, 1987.

Liu J., Moyankova D., Djilianov D., Deng X.: Common and specific mechanisms of desiccation tolerance in two Gesneriaceae resurrection plants. Multiomics evidences. Front. Plant Sci. 10: 1067, 2019.

McDonald A.E., Ivanov A.G., Bode R. et al.: Flexibility in photosynthetic electron transport: the physiological role of plastoquinol terminal oxidase (PTOX). - BBA-Bioenergetics 1807: 954-967, 2011.

Morse M., Rafudeen M.S., Farrant J.M.: An overview of the current understanding of desiccation tolerance in the vegetative tissues of higher plants. - In: Turkan I. (ed.): Advances in Botanical Research. Vol. 57. Pp. 319-347. Elsevier, Amsterdam 2011.

Oliver M.J., Tuba Z., Mishler B.D.: The evolution of vegetative desiccation tolerance in land plants. - Plant Ecol. 151: 85100, 2000.

Peeva V., Cornic G.: Leaf photosynthesis of Haberlea rhodopensis before and during drought. - Environ. Exp. Bot. 65: 310-318, 2009.

Péli E.R., Mihailova G., Petkova S. et al.: Differences in physiological adaptation of Haberlea rhodopensis Friv. leaves and roots during dehydration-rehydration cycle. - Acta Physiol. Plant. 34: 947-955, 2012.

Petrova G., Moyankova D., Nishii K. et al.: The European paleoendemic Haberlea rhodopensis (Gesneriaceae) has an Oligocene origin and a Pleistocene diversification and occurs in a long-persisting refugial area in Southeastern Europe. Int. J. Plant Sci. 176: 499-514, 2015.

Popova A.V., Dobrev K, Velitchkova M., Ivanov A.G.: Differential temperature effects on dissipation of excess light energy and energy partitioning in lut2 mutant of Arabodopsis thaliana under photoinhibitory conditions. - Photosynth. Res. 139: 367-385, 2019.

Rakić T., Lazarević M., Jovanović Ž.S. et al.: Resurrection plants of the genus Ramonda: prospective survival strategies Unlock further capacity of adaptation, or embark on the path of evolution? - Front. Plant Sci. 4: 550, 2014.

Savitch L.V., Ivanov A.G., Krol M. et al.: Regulation of energy partitioning and alternative electron transport pathways during cold acclimation of lodgepole pine is oxygen dependent. Plant Cell Physiol. 51: 1555-1570, 2010.

Sgherri C., Stevanović B., Navari-Izzo F.: Role of phenolic in the antioxidative status of the resurrection plant Ramonda serbica during dehydration and rehydration. - Physiol. Plantarum 112: 478-485, 2004.

Tan T., Sun Y., Luo S. et al.: Efficient modulation of photosynthetic apparatus confers desiccation tolerance in the resurrection plant Boea hygrometrica. - Plant Cell Physiol. 58: 1976-1990, 2017.

van Kooten O., Snel J.F.: The use of chlorophyll fluorescence nomenclature in plant stress physiology. - Photosynth. Res. 25: 147-150, 1990.

Velitchkova M., Popova A.: High light-induced changes of $77 \mathrm{~K}$ fluorescence emission of pea thylakoid membranes with altered membrane fluidity. - Bioelectrochemistry 67: 81-90, 2005.

Vertucci C.W., Farrant J.M.: Acquisition and loss of desiccation tolerance. - In: Kigel J., Galili G. (ed.): Seed Development and Germination. Pp. 237-271. Marcel Dekker, New York 1995.

Živković T., Quartacci M.F., Stevanović B. et al.: Low-molecular weight substances in the poikilohydric plant Ramonda serbica during dehydration and rehydration. - Plant Sci. 168: 105-111, 2005.

(C) The authors. This is an open access article distributed under the terms of the Creative Commons BY-NC-ND Licence. 